\title{
Pluribus Ergo Existentibus Centris: Explanations, Descriptions, and Copernicus
}

\author{
By: David Marshall Miller
}

Historians of science have extensively examined the ultimately affirmative reception of Nicolaus Copernicus's heliocentric astronomy in the Scientific Revolution it helped bring about. Yet here remains something of a puzzle. Namely, what motivated Copernicus to propose an alternative to the Ptolemaic geocentric theory in the first place? Ptolemy's system had been accepted for over a millennium, unaltered in essence and successively refined in application since first set down in the second century. Yet, at the beginning of the sixteenth century, Copernicus saw Ptolemaic astronomy as somehow inadequate. There was some problem with the geocentric system that Copernicus took it upon himself to solve. What was that problem?

On many interpretations, theoretical innovation is motivated only by failures at the interface between the theory (taken as a whole) and experience, so new theories are generated only in the face of anomalous or recalcitrant phenomena. Most famously, this is the view of Thomas Kuhn, who argued that new scientific "paradigms" are adopted when anomalies overwhelm predominant theories. But this view is also perhaps the most enduring legacy of twentieth-century empiricism in the philosophy of science. It was a core tenet of logical positivism that theories succeed insofar as they "save the phenomena," and even a postpositivist like Quine held that science is tested by the "tribunal of sense experience."

However, Copernicus cannot have been motivated by empirical failure, since the corpus of astronomical observations he sought to accommodate had remained largely unaltered since the Alfonsine tables were compiled in the thirteenth century. There was no outstanding, extensive set of problematic observations, either newly-discovered or slowly accumulated, that demanded novel explanation. Indeed, even in the end, the Copernican system did not appreciably improve predictive accuracy over its predecessors. Copernicus, moreover, was only one of several astronomers of his generation to propose alternatives to the Ptolemaic system. Copernicus's work also generated a great deal of interest even before the publication of De Revolutionibus Orbium Coelestium in 1543. Thus, Copernicus's contemporaries attributed, even before it was widely understood, great significance in his view, which is to say they took it seriously as a possible solution to some problem. Again, what was that problem?

Since antiquity, natural philosophers had ascribed uniform rotations to the heavens. This motion, it was explained, resulted from the near perfection of the celestial bodies themselves. However, the motions of the planetary bodies are not uniform. They exhibit several "anomalies"-irregular digressions from uniform circular motion. This, then, was the astronomical project: how to coordinate that which could be explained-uniform rotation- with the irregular appearances of the heavens. This "coordination" was to be carried out by a descriptive system. The celestial phenomena were to be represented in such a way that the explanatory principle at work could account for all of the elements of the representation. To put this another way, the phenomena had to be formulated into explananda that could be linked to the available explanans. The physical explanation would then apply to the description, and the description would convey the explanation to the observed phenomena. A successful astronomical theory, then as now, would enable the application of explanatory power from the physical principles to the observed phenomena via the description of those phenomena.

By the same token, an astronomical theory could fail at two distinct interfaces: that between 
phenomena and description and that between description and explanation. In the first case, the descriptions of phenomena derivable from the theory-e.g., the predictions generated by the theoryfail to correspond to experience. This is an empirical failure. In the second case, the phenomena are described in such a way that they cannot be satisfactorily explained. The physical principles, as explanantia, do not lead to the descriptions, as explananda. This is an explanatory failure.

Ptolemaic astronomy was remarkably empirically successful, but it suffered a significant explanatory failure. Even in antiquity, astronomers and philosophers alike noticed that physical explanations depended on the stipulation of a single, universal center, and could not be made to account for a descriptive system-like Ptolemy's - that posited a multiplicity of motions around a multiplicity of centers. Nevertheless, the empirical success of Ptolemaic astronomy proved attractive, and the problem of multiple centers was explicitly set aside in late antiquity. In the middle ages, however, this "Ptolemaic Compromise" was rejected by Arabic philosophers, especially Averroës, who insisted that Ptolemaic astronomy could not be reconciled with physical explanations and therefore had to be rejected. The problem of multiple centers, they said, could not be surmounted.

A resurgent Averroism in the Renaissance universities where Copernicus studied renewed interest in the gaps between Ptolemaic descriptions and physical explanations, especially the problem of multiple of centers. Thus, Ptolemaic astronomy's explanatory failure led Copernicus (and others) to attempt new reconciliations between observational astronomy and physics. In fact, Copernicus was a somewhat conservative Averroist. He did not reject Ptolemy outright, as did some of his peers. Instead, he tried to preserve as much as possible of the Ptolemaic system, rejecting only equants, which he thought were too egregious departures from the physical "first principles" of astronomy. In the end, Copernicus did not solve the problem Averroës had raised. Like Ptolemy, he posited a multiplicity of centers, contrary to the demands of Aristotelian physics. Subsequent authors continued to struggle with the explanatory problem of multiple centers in Copernicus's heliocentric astronomy, and were thus led to seek novel and ultimately non-Aristotelian explanations of the heavens and the natural world-ones that did not depend on the stipulation of a center at all. A change of descriptions to save explanations led to changes of explanations to save descriptions.

This historical discussion integrates several issues in the philosophy of science regarding scientific epistemology and scientific change. In particular, notice the layered model of scientific knowledge at work. Scientific theories, insofar as they are attempts to explain natural phenomena, necessarily involve two distinct epistemic levels: explanatory principles and descriptions. Explanatory principles have no explanatory force-they are not explanations of anything at all-unless they are coordinated to some feature of the world by a description. One must specify what is happening before once can attempt to say why it is happening. Descriptions are part of a theory. They are necessary to bring phenomena under explanations, and thus necessary to make them intelligible.

This layered model of scientific theory leads, in turn, to a characterization of scientific change. To change a theory is to alter either epistemic layer within it. A new theory is generated by altering either descriptions or explanations. In both cases, the phenomena are made intelligible anew. Thus, a scientist might respond to the failures of a prior theory in a variety of ways. She might alter explanations to make phenomena intelligible as previously described. She might alter the descriptions of the phenomena to bring them into line with explanations. Copernicus pursued this last option in the face of the explanatory failure of Ptolemaic astronomy, though he inspired subsequent authors to follow the first option-new explanations-to solve explanatory failures in his own theory. 